\title{
MARITAL STATUS AND EDUCATION AS RISK FACTORS FOR COLORECTAL CANCER
}

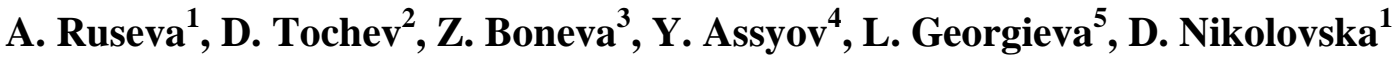 \\ ${ }^{1}$ Clinic of Gastroenterology, Medical Institute - Ministry of Interior, Sofia, Bulgaria \\ ${ }^{2}$ Department of Biotechnology, University of Chemical Technology and Metallurgy, Sofia, Bulgaria \\ ${ }^{3}$ Department of Endocrinology, Medical Institute- Ministry of Interior, Sofia, Bulgaria \\ ${ }^{4}$ Clinic of Endocrinology, Alexandrov's Hospital, Sofia, Bulgaria \\ ${ }^{5}$ Department of Social Medicine, Faculty of Public Health, Medical University, Sofia, Bulgaria
}

\begin{abstract}
Colorectal cancer (CRC) is a socially significant disease. It is often looking for its relationship with lifestyle and heredity. For its development, factors as marital status and education are also important. The purpose of the study is to evaluate the influence of the marital status and education on the colorectal cancer risk. The time of impact is five years, before the diagnose is made.

There are 540 persons participating in the study. Participants are separated into two groups - cases and control group. Both groups are unified by known confounders gender and age. Information is collected via questionnaire and as interview. Data is introduced and processed with IBM SPSS Statistics 22.0. For the level of significance, whereby the null hypothesis is rejected, we accepted $\mathrm{p}$ $<0.05$.

We demonstrate the definitive influence of the education as a risk factor for CRC. Participants with secondary and primary education have higher risk of developing colorectal neoplasm, compared to those with higher education. We also establish that marital status had protective effect in some cases of CRC.
\end{abstract}

Key wards: colorectal cancer, risk factors, marital status, education

\section{INTRODUCTION}

Colorectal cancer is the second most common neoplasm in Bulgaria. (National Statistical Institute, 2017) The frequency, big expenses for its treatment, disability and psychic trauma of the patient determine it as a social significant disease.

The connection between colorectal cancer and different risk factors is established from many years. $(1,2)$. These factors may be divided into two groups- environmental and hereditary factors. The first group includes lifestyle (e.g. nutrition, alcohol consumption, smoking, physical activity), medication, concomitant diseases, environment $(3,4)$. For the

\footnotetext{
*Correspondence to: Adriana Ruseva, Clinic of Gastroenterology, Medical Institute- Ministry of Interior, Blvd. "Skobelev"79 Sofia, Bulgaria, E-mail:dr_aruseva@abv.bg,003599821358
}

development of this cancer importance have socio-economic factors as marital status and the level of education. $(5,6)$ It is supposed that heredity has great impact on this carcinoma emergence. (7)

Despite of the numerous studies on this topic, there is no certain conclusion about association between defined risk factors and colorectal cancer. For some factors a positive connection is found and for others the data is inconsistent and speculative.

Aim of the study is to find how the marital status and educational level influenced the risk of colorectal cancer, in males and females with period of impact five years before the diagnose was made. We additionally aim to determine the meaning of the studied factors for the different localization of the carcinoma. 


\section{MATERIALS AND METHODS}

There are 540 participants in our study with an average age of 62, 69 years, in diapason from 22 to 86 years. Males are $307(57 \%)$ and females $233(43 \%)$.

Participants of the research are divided into two groups: cases (patients with colorectal cancer) and controls. The two groups are statistically uniform by known confounders' gender and age.

The most frequent localization of the carcinoma, among the studied people, is rectum- 101 (37\%) of cases, followed by distal colon- 94 patients $(35 \%)$. The less are patient with proximal localization of the cancer in the colon- 75 (28\%).

The information about the patient is collected by specially made for the goals of the study questionnaire, and by an interview. Data is processed with statistical program IBM SPSS Statistics 22.0. For the level of significance in which the null hypotheses is rejected we assume $\mathrm{p}<0,05$.

\section{RESULTS}

Education is significant factor for nascence of colorectal cancer, in our study. Secondary education is connected with $67 \%$ higher risk than high education, reported for entire sample. The risk is $81 \%$ higher in men, about 2, 5 times higher in proximal localization of carcinoma, and 2,3 times in combination men with proximal localization of the tumor, and 3,2 times in women with proximal localization of the tumor. Primary education leads to significantly higher risk, varying between 3,3 and 13,5 times in combination males with proximal localization of the cancer, compared to high education. We demonstrate the positively matter of this factor for developing CRC. Participants with secondary education have higher risk, compared with those with high education. (Table 1)

We also establish that marital status have a protective role only for the colorectal cancer localized in the proximal colon, and it is valid only for the comparison married man to widower. The protective effect is about $80 \%$. There is no statistically significant association between the researched factor and colorectal cancer risk, in all other cases. (Table 2)

Table 1. Results of logistic regression analysis of the factor education

\begin{tabular}{|c|c|c|c|c|c|c|}
\hline \multirow[t]{2}{*}{ Group } & \multirow[t]{2}{*}{ Localisation } & \multirow[t]{2}{*}{ Comparison } & \multirow[t]{2}{*}{ OR } & \multicolumn{2}{|c|}{$95 \% \mathrm{CI}$} & \multirow[t]{2}{*}{$\mathbf{p}$} \\
\hline & & & & $\begin{array}{l}\text { Lower } \\
\text { border }\end{array}$ & $\begin{array}{l}\text { Upper } \\
\text { border }\end{array}$ & \\
\hline \multirow{2}{*}{ All } & \multirow{2}{*}{ All } & Secondary/High & 1,668 & 1,150 & 2,420 & 0,007 \\
\hline & & Primary/ High & 4,709 & 2,461 & 9,010 & $<0,001$ \\
\hline \multirow{2}{*}{ Men } & \multirow{2}{*}{ All } & Secondary / High & 1,806 & 1,116 & 2,922 & 0,016 \\
\hline & & Primary / High & 8,877 & 2,917 & 27,013 & $<0,001$ \\
\hline \multirow{2}{*}{ Women } & \multirow{2}{*}{ All } & Secondary / High & 1,588 & 0,846 & 2,980 & 0,150 \\
\hline & & Primary / High & 3,273 & 1,334 & 8,028 & 0,010 \\
\hline \multirow{2}{*}{ All } & \multirow{2}{*}{$\begin{array}{l}\text { Proximal } \\
\text { colon }\end{array}$} & Secondary / High & 2,527 & 1,370 & 4,660 & 0,003 \\
\hline & & Primary / High & 5,835 & 2,342 & 14,537 & $<0,001$ \\
\hline \multirow{2}{*}{ All } & \multirow{2}{*}{ Distal colon } & Secondary / High & 1,373 & 0,819 & 2,301 & 0,229 \\
\hline & & Primary / High & 3,358 & 1,452 & 7,765 & 0,005 \\
\hline \multirow{2}{*}{ All } & \multirow{2}{*}{ Rectum } & Secondary / High & 1,497 & 0,888 & 2,524 & 0,130 \\
\hline & & Primary / High & 5,511 & 2,528 & 12,013 & $<0,001$ \\
\hline \multirow{6}{*}{ Men } & \multirow{2}{*}{ Proximal colon } & Secondary / High & 2,295 & 1,060 & 4,967 & 0,035 \\
\hline & & Primary / High & 13,538 & 3,566 & 51,397 & $<0,001$ \\
\hline & \multirow{2}{*}{ Distal colon } & Secondary / High & 1,362 & 0,692 & 2,681 & 0,371 \\
\hline & & Primary / High & 4,783 & 1,188 & 19,251 & 0,028 \\
\hline & \multirow{2}{*}{ Rectum } & Secondary / High & 1,989 & 1,033 & 3,828 & 0,040 \\
\hline & & Primary / High & 10,476 & 2,991 & 36,691 & $<0,001$ \\
\hline \multirow{6}{*}{ Women } & \multirow{2}{*}{ Proximal colon } & Secondary / High & 3,176 & 1,023 & 9,863 & 0,046 \\
\hline & & Primary / High & 3,273 & 0,700 & 15,291 & 0,132 \\
\hline & \multirow{2}{*}{ Distal colon } & Secondary / High & 1,412 & 0,594 & 3,357 & 0,435 \\
\hline & & Primary / High & 2,909 & 0,905 & 9,349 & 0,073 \\
\hline & \multirow{2}{*}{ Rectum } & Secondary / High & 1,059 & 0,432 & 2,595 & 0,901 \\
\hline & & Primary / High & 3,636 & 1,180 & 11,207 & 0,025 \\
\hline
\end{tabular}


Table 2. Results of logistic regression analysis of the factor marital status

\begin{tabular}{|c|c|c|c|c|c|c|}
\hline \multirow[t]{2}{*}{ Group } & \multirow[t]{2}{*}{ Localization } & \multirow[t]{2}{*}{ Comparison } & \multirow[t]{2}{*}{ OR } & \multicolumn{2}{|c|}{$95 \% \mathrm{CI}$} & \multirow[t]{2}{*}{$\mathbf{p}$} \\
\hline & & & & $\begin{array}{l}\text { Lower } \\
\text { border }\end{array}$ & $\begin{array}{l}\text { Upper } \\
\text { border }\end{array}$ & \\
\hline \multirow[t]{9}{*}{ Men } & \multirow[t]{3}{*}{ Proximal colon } & Unmarried/Widow & 0,245 & 0,036 & 1,658 & 0,149 \\
\hline & & Married/ Widow & 0,208 & 0,065 & 0,661 & 0,008 \\
\hline & & Divorced/ Widow & 0,000 & 0,000 & 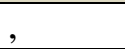 & 0,999 \\
\hline & \multirow[t]{3}{*}{ Distal colon } & Unmarried / Widow & 1,714 & 0,228 & 12,890 & 0,601 \\
\hline & & Married / Widow & 0,977 & 0,190 & 5,022 & 0,978 \\
\hline & & Divorced / Widow & 1,000 & 0,063 & 15,988 & 1,000 \\
\hline & \multirow[t]{3}{*}{ Rectum } & Unmarried / Widow & 0,286 & 0,023 & 3,523 & 0,328 \\
\hline & & Married / Widow & 0,818 & 0,197 & 3,390 & 0,782 \\
\hline & & Divorced / Widow & 2,000 & 0,241 & 16,612 & 0,521 \\
\hline \multirow[t]{9}{*}{ Women } & \multirow[t]{3}{*}{ Proximal colon } & Unmarried / Widow & 3,000 & 0,170 & 53,051 & 0,454 \\
\hline & & Married / Widow & 0,873 & 0,360 & 2,118 & 0,765 \\
\hline & & Divorced / Widow & 0,429 & 0,046 & 3,974 & 0,456 \\
\hline & \multirow[t]{3}{*}{ Distal colon } & Unmarried / Widow & 0,000 & 0,000 & & 1,000 \\
\hline & & Married / Widow & 0,736 & 0,334 & 1,621 & 0,447 \\
\hline & & Divorced / Widow & 0,593 & 0,108 & 3,265 & 0,549 \\
\hline & \multirow[t]{3}{*}{ Rectum } & Unmarried / Widow & 0,000 & 0,000 & 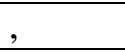 & 1,000 \\
\hline & & Married / Widow & 1,025 & 0,429 & 2,452 & 0,955 \\
\hline & & Divorced / Widow & 1,286 & 0,273 & 6,050 & 0,750 \\
\hline
\end{tabular}

\section{DISCUSSION}

Socio-economic status is directly connected with the risk of carcinomas including colorectal cancer. $(5,8,9)$ This status is evaluated by a number of indicators. The most important and with highest separately meaning is education. (5) Within a large prospective study in USA, it is established that frequency of colorectal cancer is considerably higher among people with lower educational and socio-economical level, even when other potentially interfering factors are take into account. It is also found that this connection is stronger for rectal than a colon cancer. For the proximal colon cancer such a connection is not determined. (10) Italian study conducted between 1985 and 1996 explore the influence of socio-economic status on colorectal cancer risk. Differences are observed regarding places of habitation, calendar period and localization of the carcinoma in the colon. The results show that the risk of colon neoplasm is significantly higher in individuals with lower educational level, while for the rectal cancer such a connection is not inspect. (11) There are reverse results, however. European prospective study demonstrates inverse association between lower educational level and colorectal cancer risk, especially in the proximal colon, females, and in people from Western Europe. $(12,13) \mathrm{We}$ demonstrate the explicit importance of the education factor for the colorectal cancer risk in Bulgarian population. The positive effect of the higher education on the risk of developing CRC (6) can be explained with the fact that people with lower education have lower socio-economic status, lower medical acquirements, and lower tendency towards performing screening and more difficult access to medical care. $(14,15$, 16) Discussing this subject, we have to note that people with lower educational and socioeconomic status have different sanitary and nutritional habits, who are prerequisite for developing colorectal cancer.

Important element of social existence is marital status. Decades of studies demonstrate that marriage have strong positive effect on human health and survival. $(17,18)$ Large research in America proves the protective effect of the marriage on the health. Its matter may be connected with numerous of pathophysiological mechanisms. Husband plays a critical role in observation and modeling the health behavior. (18) Studies in the total population declare conflicting results in regard to influence of the marriage on the different type of carcinomas. Some of the investigations show positive connection of the marriage and surviving after neoplasm in males and females, but mostly in females. (17, 18) Little is known about the role of the 
marital status in the risk of developing colorectal cancer. Some of surveys significates protective effect, other report mixed effect, and third don't display any connection. In retrospective longitudinal cohort study is observed that married patients have serious positive effect on the survival after carcinoma operation, compared to unmarried. The connection remains after revaluation of demographic factors and tumor characteristics. This study shows decreasing of overall mortality with 23\%. (19) Research in USA is analyzing the meaning of marital status taking into account sex, race, smoking, accompanying diseases, tumor stage, treatment methods, type of operation and others. It is established that marital status has different meaning for survival in men and women. Married men have protective effect, while in women such effect is not demonstrated. (20) We observed protective effect only for the married men to widow and proximal localization of the tumor in the colon.

The explanation for the connection between the marital status and health can be considered in two categories. The first one is that people in good health are more inclined to get married and stay married. The other one is that the marriage is a form of a social support and increases the propensity of the patients to look for a medical help on time, that is why the diseases are discovered in earlier stages. That people more frequent conduct screening for different diseases, take the prescribed medicines and are subjected to earlier radical interventions. There is increasing of the inclination to accept radio and chemotherapy. $[17,18,19,21]$ The importance of the financial help is also not too small. [19]

\section{CONCLUSION}

As a result of our study we can summarize that not only broad studied factors from lifestyle and heredity have impact on the development of colorectal cancer. Marital status and education have a great role too. Conducting more investigations in this line, including more people and taking under attention more factors as well as the combination between them is necessary. Establishing the connection between risk of CRC and variable risk factors (like education) gives the opportunity for prophylaxis of this frequent and socially significant disease.

\section{REFERENCES}

1. World Cancer Research Fund / American Institute for Cancer Research. Continuous
RUSEVA A., et al. Update Project: Colorectal Cancer Report 2010 Summary. Food, Nutrition, Physical Activity, and the Prevention of Colorectal Cancer. 2011

2. Singh S, Singh H, Singh P, Hassan- Murad $M$, and Limburg P. Antidiabetic Medications and the Risk of Colorectal Cancer in Patients with Diabetes Mellitus: A Systematic Review and Meta-analysis. Cancer Epidemiol Biomarkers PrevDecember 2013 22; 2258

3. Na H, Oliynyk S. Effects of physical activity on cancer prevention, Nutrition and Physical Activity in Aging, Obesity, and Cancer, Jul 2011: pp 176-183, 27

4. Lim H, Park B. Cohort study on the association between alcohol consumption and the risk of colorectal cancer in the Korean elderly. J Prev Med Pub Health, 2008; 41: 23-29

5. Sharpe K, McMahon A, Raab G, Brewster D, and Conway D. Association between Socioeconomic Factors and Cancer Risk: A Population Cohort Study in Scotland (19912006). PLoS One. 2014; 9(2).

6. Tavani A, Fioretti F, Franceschi S, Gallus S, Negri E, Montella M, et al. Education, socioeconomic status and risk of cancer of the colon and rectum. Int J Epidemiol. 1999 Jun;28(3):380-5.

7. Murff H, Peterson N, Greevy R, et al. Impact of patient age on family cancer history. Genet Med, 2006; 8 (7): 438-42.

8. Cowan C, Hauser R , Kominski R, Levin $\mathrm{H}$, Lucas S, Morgan S, et al. Improving the Measurement of Socioeconomic Status for the National Assessment of Educational Progress: A Theoretical Foundation. Recommendations to the National Center for Education Statistics Nov. 2012

9. Galobardes B, Shaw M, Lawlor D, Lynch J, Smith G. Indicators of socioeconomic position (part 1). J Epidemiol Community Health 2006; 60: 7-12

10.Doubeni C, Laiyemo A, Major J, Schootman M, Lian M, Park Y, et al. Socioeconomic status and the risk of colorectal cancer: an analysis of more than a half million adults in the National Institutes of Health-AARP Diet and Health Study. Cancer. 2012 Jul 15;118(14):363644.

11.Tavani A, Fioretti F, Franceschi S, Gallus S, Negri E, Montella M, et al. Education, socioeconomic status and risk of cancer of the colon and rectum. Int J Epidemiol. 1999 Jun;28(3):380-5. 
12.Leufkens A, Van Duijnhoven F, Boshuizen H, Siersema P, Kunst A, Mouw T, et al. Educational level and risk of colorectal cancer in EPIC with specific reference to tumor location. Int J Cancer. 2012 Feb $1 ; 130(3): 622-30$.

13.Leufkens A, Van Duijnhoven F, Boshuizen H, Siersema P, Kunst A, Mouw T, et al. Educational level and risk of colorectal cancer in EPIC with specific reference to tumor location. Int J Cancer. 2012 Feb 1;130(3):622-30.

14.Atkin W, Kralj-Hans I, Wardle J, Duffy S. Randomised trials of flexible sigmoidoscopy. BMJ.2010;341:c4618.

15.Brenner H, Hoffmeister M, Arndt V, Stegmaier C, Altenhofen L, Haug U. Protection from right- and left-sided colorectal neoplasms after colonoscopy: population-based study. $J$ Natl Cancer Inst.2010;102(2):89-95.

16.Doubeni C, Laiyemo A, Klabunde C, Young A, Field T, Fletcher R. Racial and ethnic trends of colorectal cancer screening among Medicare enrollees. Am J Prev Med. 2010;38(2):184-91
RUSEVA A., et al.

17.Lai K, B. Stotler. Marital Status and Colon Cancer Stage at Diagnosis. The Open Colorectal Cancer Journal, 2010; 3: 5-11

18. Wanga L, Wilson S, Stewart D, Hollenbeak C. Marital status and colon cancer outcomes in US Surveillance, Epidemiology and End Results registries: Does marriage affect cancer survival by gender and stage? The Cancer Epidemiology 35 (2011) 417-422

19.Li Z, Wang K, Zhang X, Wen J, Tusconi M. Marital status and survival in patients with rectal cancer: A population-based STROBE cohort study Medicine: May 2018. Volume 97 . Issue 18

20.Justiniano C, Z. Xu, A. Becerra, C. Aquina, F. Boscoe, M. Schymura, et al. Impact of marital status on colorectal cancer (CRC) disease-specific survival in New York state. Journal of clinical oncology 35, 2017 ,no. 15

21.Wanga L, Wilson S, Stewart D, Hollenbeak C. Marital status and colon cancer outcomes in US Surveillance, Epidemiology and End Results registries: Does marriage affect cancer survival by gender and stage? The Cancer Epidemiology 35 (2011) 417-422 